\title{
Clinical Implications Related to the Use of Drugs Illicit and Licit During the Pregnancy
}

\author{
Jair Alves Maia, Alesandro Lima Rodrigues, Denisa Rosa de Souza, Mediã Barbosa Figueiredo \\ Department of Health Sciences, College Baron of River White, River White Acre, Brazil
}

Email address:

jairalvesac@hotmail.com (J. A. Maia)

\section{To cite this article:}

Jair Alves Maia, Alesandro Lima Rodrigues, Denisa Rosa de Souza, Mediã Barbosa Figueiredo. Clinical Implications Related to the Use of Drugs Illicit and Licit During the Pregnancy. Clinical Neurology and Neuroscience. Vol. 2, No. 2, 2018, pp. 27-32.

doi: $10.11648 /$ j.cnn.20180202.12

Received: June 15, 2018; Accepted: June 27, 2018; Published: July 24, 2018

\begin{abstract}
Introduction: the use of drugs has been growing quickly and continuously in the general population, where teenagers, young, old and even children are entering this world intense and devastating. Already in women users this picture is even more worrying when it comes to consumption during pregnancy. Objective: to identify the most commonly used drugs for pregnant women who performed prenatal care in a primary care Reference Unit of Rio Branco, Acre, in the period from 28 August to 28 September 2017. Methodology: this is a cross-sectional field study of observational, descriptive, exploratory character, basic quantitative approach on drug use by women during the gestational period. Results: the analysis of the data collected has identified that during the period were pregnant gestational use of substances: 18 (60\%) used alcohol, $9(30 \%)$ smoked cigarettes, $2(6.7 \%)$ was associated with use of alcohol and cigarettes and $1(3.3 \%)$ reported use of alcohol, cigarette, marijuana, cocaine and crack, concurrently. Conclusion: the use of drugs during the gestational period brings multiple consequences to the body of the mother and the fetus, of which are intrauterine growth restricted, congenital malformations, miscarriage, premature labour, premature separation of placenta, placenta previa and death Fetal. And it is important to note that the professionals working on prenatal consultation strategies should be used to prevent and relieve the drug use in gestational period.
\end{abstract}

Keywords: Pregnancy, Primary Health Care, Drugs, Fetal Development

\section{Introduction}

"According to the information of the United Nations Office on drugs and Crime (UNODC), the use of drugs in the world's population remains regular and about 250 million people are using any or various drugs, which corresponds to $5 \%$ of the global population with between the ages of 15 and 64 years, have utilized some type of drugs [1]".

"In Brazil, the use of drugs constitutes a serious public health problem, expanding and reached all social classes, age groups and genres in our society. That's what demonstrates the use of household survey (II) psychotropic drugs in the country occurred in 2005 , with participants with age range between 12 and 65 years, held in more than 108 cities with a total of 3,301 people, 7,939 men and 4,638 women reported to be some kind of drugs users [2]. Being that most of the participants were female.

During pregnancy, the use of licit and illicit drugs constitute a risk factor to the health of the mother and the developing fetus, the consequences and the ill effects on the fetus and the mother are devastating [3]".

"The use of these substances interfere with the natural course of the organism causes the appearance of diseases, as well as perinatal complications, bad-congenital formations, retarded fetal growth, miscarriage, premature birth and maternal death-fetal [4]"

Complementary, Kassada end contributors [5]. "claim that pregnant women drug users have a smaller membership prenatal queries, greater risks of obstetrical and fetal complications but also in General, do not participate in groups of pregnant women. The author even notes that most mothers abandon their children".

For Freire, P and Saunders [6] "prenatal care proves to be an excellent time for identification, intervention and prevention of drug use by the mother, the bond that occurs with health workers in the unit, especially the professionals 
working in maternal-fetal assistance".

In this context, outlined the present study aimed to Identify the most commonly used drugs for pregnant women who performed prenatal care in a primary care Reference Unit of Rio Branco, Acre, in the period from August to September of 2017.

\section{Method}

It is a field study of cross section of observational, descriptive, exploratory character, basic quantitative approach on drug use by pregnant women to prenatal care were held in primary care Reference Unit Dr. Claudia Vitorino, in Taquari Neighborhood in the city of Rio Branco, Acre, between the months of August and September 2017.

The identification of pregnant women users, occurred in the prenatal clinic during the anamnesis/nursing interview, following the natural course of prenatal consultation. The inclusion criteria used were: be licit or illicit drug user, be performing prenatal consultation on URAP Dr. Claudia Vitorino, age over 18 years. Sample exclusion criteria were: pregnant women who used drugs, not under 18 years.

Pregnant women who fit the criteria for inclusion was invited at the end of the query (potential participant) to compose the research. After explaining the objectives, risks and benefits of research, women who have agreed to participate and were in accordance with the terms, signed an informed consent (TFCC) in two ways. So, using the inclusion criteria of the study population was made up of a sample of 30 pregnant women.

Data collection took place from August 28 to September 28 2017, after presenting the opinion embodied, opting for apply a 05 survey closed multiple-choice questions as a means of collecting, which occurred during the query prenatal care, whose purpose was to identify the sociodemographic data and the most commonly used drugs by pregnant women.

The data obtained were selected, categorized and tabulated. And the quantification of the answers, put up in forms of charts and tables through absolute and percentage frequencies. The statistic used involved distribution of frequencies and measures of central tendency.

This study was approved by the ethics and Research Committee (CEP), with the opinion CAAE 70146017.2.0000.8028 and followed the recommendations of resolution No. 466 of 2012 National Health Council that rules on conducting research with human beings.

\section{Results}

In figure 1 , the descriptive analyses related to the age group of 30 pregnant women drug users have been answered in the prenatal clinic of the health unit. "The highest proportions of pregnant drug users were observed between the ages of 22 to 25 years of age $(36.7 \%)$, of 18 to 21 years $(33.3 \%)$ and the smallest proportion $(10 \%)$ was shown at the age of 32 to 39 years".

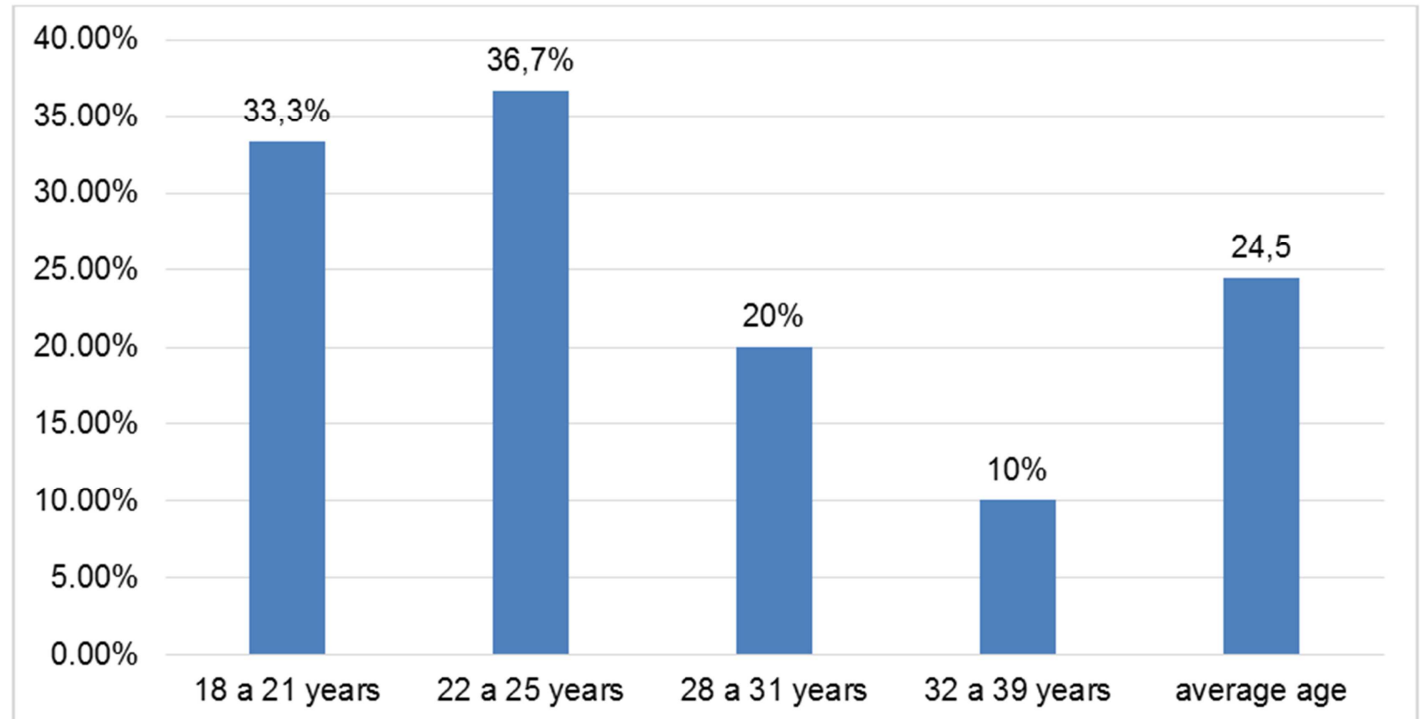

Figure 1. Age of pregnant women drug users have been answered in the unit under study In the period from 28 August to 28 September, Rio Branco, Acre, 2017.

In figure 2, the highest proportions of cases of pregnant women drug users in pregnant women with high school complete $(30 \%)$ and incomplete elementary school $(26.7 \%)$. Showed low percentages of consumption in patients with higher education incomplete or complete with $10 \%$ and $3.3 \%$, respectively. 


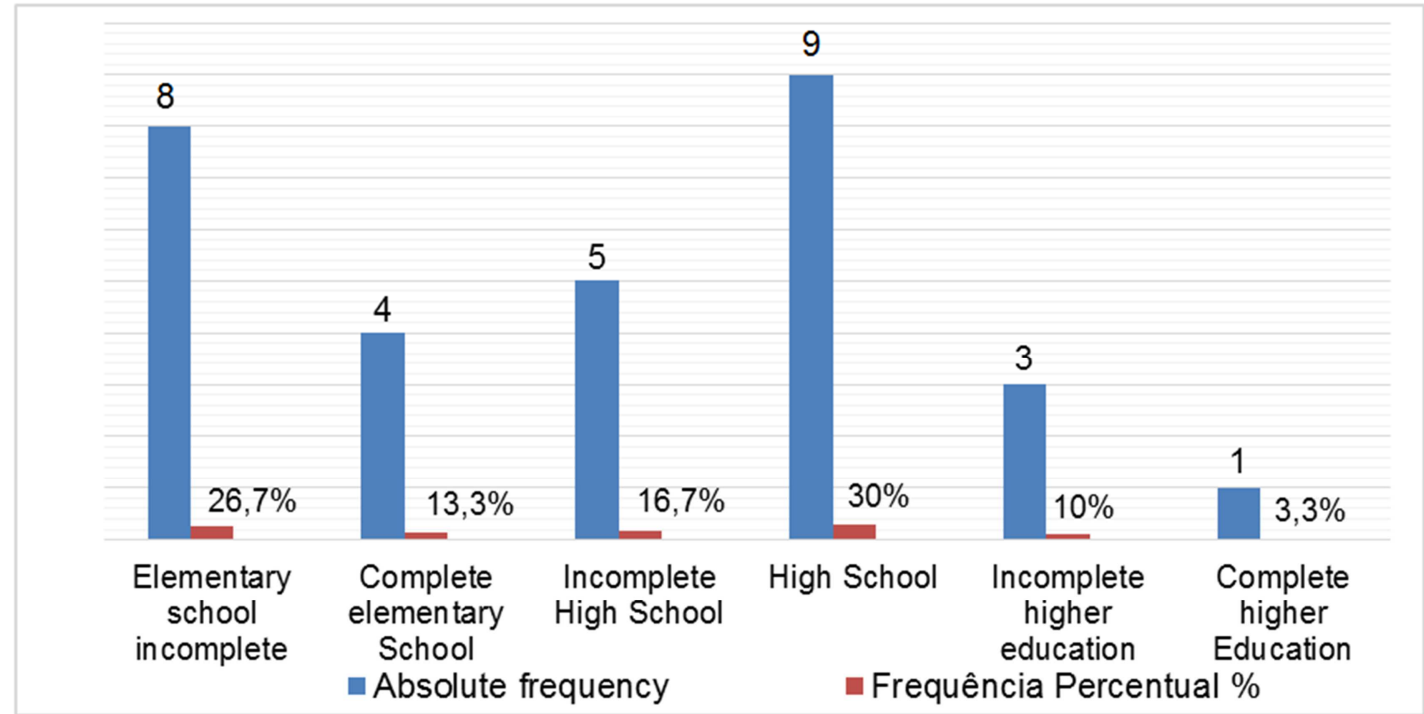

Figure 2. Distribution of pregnant women who have been treated in a health unit of Rio Branco Acre, according to the degree of education, Rio Branco Acre, 2017

In figure 3, it turns out that the highest proportions of drug use have been in married pregnant women (53.3\%), stable union $(36.7 \%)$ and the smallest percentage in single pregnancies $(10 \%)$.

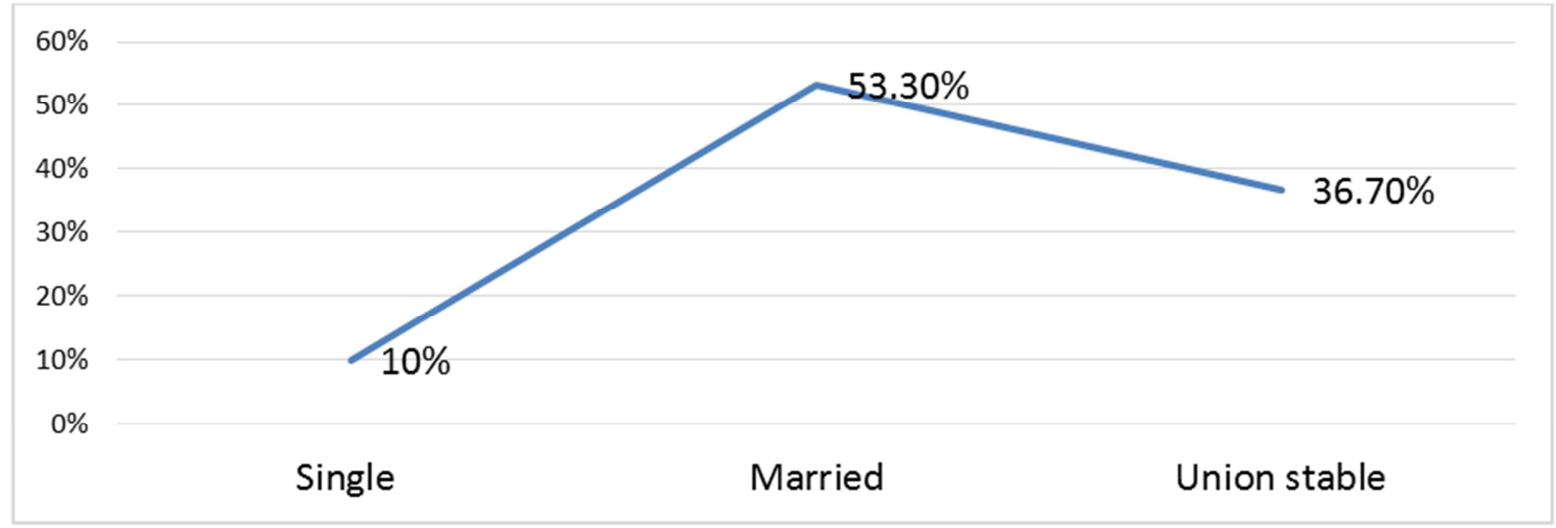

Figure 3. Distribution of pregnant women who have been treated in a health unit of Rio Branco Acre, according to the civil state, Rio Branco Acre, 2017.

According to figure 4, it can be observed that (36.7\%) of pregnant women worked in the home, $(26.7 \%)$ were unemployed, $(13.3 \%)$ were students, and $(23.3 \%)$ acted in other professions, being $(6.8 \%)$ were manicures, $(3.3 \%)$ autonomous, $(3.3 \%)$ entrepreneurs, (3.3\%) vigilantes, (3.3\%) administrative auxiliaries and (3.3\%) fiscal auxiliaries.

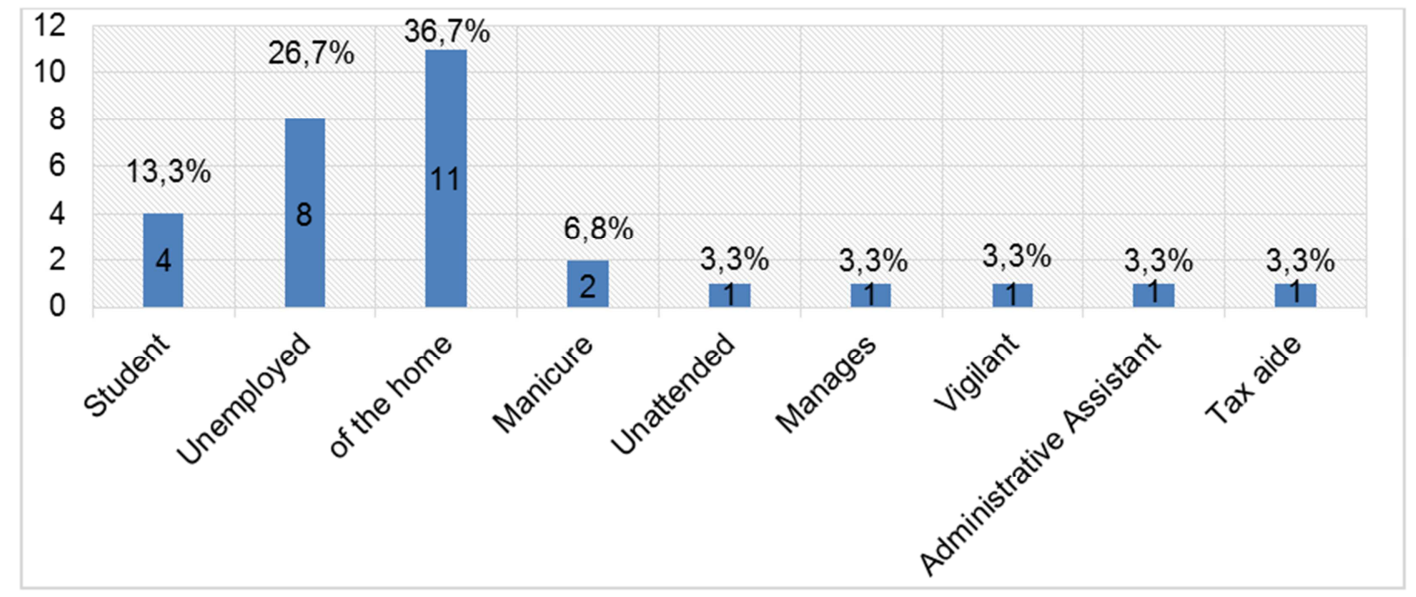

Figure 4. Distribution of pregnant women using drugs served in a health unit of Rio Branco Acre, according to the profession, Rio Branco Acre, 2017. 
In table 1 , it is observed that $60 \%$ of pregnant women mentioned alcohol use, $30 \%$ cigarette use, $6.7 \%$ associated use of alcohol and cigarette, $3.3 \%$ mentioned concomitant use of alcohol, cigarette, marijuana, cocaine and crack, respectively.

Table 1. Percentage of pregnant women drug users served in a primary care health unit in the municipality of Rio Branco Acre, according to the distribution of drug use, Rio Branco Acre, Brazil 2017.

\begin{tabular}{lll}
\hline Variável & F (A)=30 & F (\%) \\
\hline Alcohol & 18 & $60 \%$ \\
Cigarette & 09 & $30 \%$ \\
Alcohol and cigarette & 02 & $6,7 \%$ \\
Alcohol, cigarette, marijuana and Crack cocaine & 01 & $3,3 \%$ \\
\hline
\end{tabular}

\section{Discussion of the Results}

During the study period were met 187 pregnant women in the primary Care reference Unit Dr. Claudia Vitorino and these 30 pregnant women mentioned using some kind of chemical substance.

"The age range of pregnant women in figure 1 showed that the users present an age that ranged from 18 to 39 years, with an average of 24.5 years". Similar result. was found in a study with pregnant drug users carried out in there municipalities in the northwestern region of Paraná (17 to 33 years, averaging 25.7 years) [7]. "In the literature, it is observed that $85 \%$ of women drug users present between 15 to 40 years, age group is considered fértil [8]".

"In relation to the level of schooling, figure 2 showed that $26.7 \%$ of pregnant women had incomplete elementary school, $30 \%$ full high school and 3.3\% complete higher education. Similar data were found in other surveys, where $4 \%$ had the higher education, $48.61 \%$ the high school completo5 and divergently $72 \%$ the elementary school incomplete [9]".

The figure 3 presented the marital status of pregnant women in which $10 \%$ reported being single, $53.3 \%$ married and $36.7 \%$ were in stable union. "Similar result was found in a study conducted in the city of Jaws, Santa Catarina state with pregnant women and mothers who mentioned drug use, in which $5.77 \%$ declared themselves single and $94.33 \%$ married or Amasiadas [10]".

The analysis of the occupational situation/profession in figure 4 , revealed that, $13.3 \%$ played the student function, $26.7 \%$ were unemployed, $36.7 \%$ declared themselves the owner of the home and $23.3 \%$ acted in other professions. This data shows similarity to a study carried out in the municipality of Maringá, State of Paraná in which 52\% were of the home, $32 \%$ were unemployed, $4 \%$ were informed to be student and $12 \%$ played other professions [9]. "It is noted that the use of drugs during the gestational period is not restricted to a single working situation, but simultaneously to reach other professional classes".

"In table 1, it was found that among pregnant women who reported to be a drug user, $60 \%$ referred to the use of alcohol", which can be observed that alcohol was the chemical substance most used by pregnant women in this study. Similar drug choice pattern was found in a study conducted with pregnant drug users with a percentage of $75 \%$ [7].

"Alcohol intake during the gestational period brings consequences for mother and especially for the fetus, where their consumption in the first trimester can cause spontaneous miscarriage and severe physical deformations". There is a view that the first quarter corresponds to the period in which the formation of the neural tube and the organ [11].

In a research entitled alcohol and its consequences showed that the placenta is easily permeable to the passage of alcohol to the fetus, so the content of the alcohol in the blood is almost equal to that of the mother when ingested, that because when suffering metabolization becomes aldehyde Acetic, as a primary effect occurs a vasoconstriction in the umbilical cord and placenta, which may increase the duration of the fetal exposure due to the reduction of the blood [12].

According to the study of Dos-Santos and contributors [13], "alcohol presents a high degree of toxicity and shows that consumption of only $30 \mathrm{ml} /$ day can cause spontaneous abortion, misformations, anomalies of the Central nervous system, detachment of placenta, Restricted intrauterine growth, prematurity, cardiac alterations, fetal alcohol syndrome and premature childbirth".

"Fetal Alcohol syndrome is one of the main consequences of the use of alcohol being characterized by a set of damage of the Central nervous system, since the organ most affected to the effects of use during pregnancy is the brain, thus producing changes Neurological, such as development lag, physical abnormalities, intellectual deficiencies, as well as cognitive, emotional and behavioral problems [14]".

For dam, alcohol consumption favors the use of other drugs, causes minor adherence to prenatal care, insufficient gestational weight gain, increased juice and gastric acidity with decreased airway protection reflexes, "which is a great risk From Broncoaspiration [3]”.

It is noted that the cigarette was the second most mentioned drug and consumed with a percentage of $30 \%$ by pregnant women who performed prenatal care in the health unit under study. This result is similar to that found in another search with a result of $28 \%$ in the use of cigarette during the gestation [9].

"The cigarette is a substance of high toxicity, possessing almost 5000 components and more than 40 agents carcinogens [15]. In pregnancy, when smoked the cigarette compromises the health of the fetus with emergence of pathologies arising from the action/effects of carbon monoxide and nicotine, which can manifest from the Intraútero period to the slave life [16]".

Nicotine is one of several components of the cigarette, which when inhaled crosses the placental barrier reduces the blood flow of the placenta with vasoconstrictor of the vessels of the uterus and consequently decreases the supply of oxygen and nutrients to the fetus [17].

According to information from the National Cancer Institute (INCA) a single smoked cigarette accelerates in minutes the concepto heart rate due to the effects of nicotine 
on the cardiac system. In addition, they may cause miscarriages, premature birth, placenta previa, premature detachment of placenta, bleeding and fetal death [18].

The use of alcohol and associated cigarette evidenced a percentage of $6.7 \%$ by pregnant women in this study. In the research of hiking and contributors [19]. held in the maternity School of Assisi Chateaubriand (MEAC), with pregnant women in the municipality of Fortaleza, State of Ceará, showed that $4.5 \%$ reported use of alcohol and cigarette during the gestational period.

As for the use of lawful and illicit drugs concomitantly, it was identified that only $3.3 \%$ of the sample mentioned use of alcohol, cigarettes, marijuana, cocaine and crack respectively The result of $1.5 \%$ was found in the research of hiking and contributors [19]. in which pregnant women mentioned simultaneous use of illicit drugs, alcohol and cigarettes in pregnancy.

In the fetus, the drug affects the central nervous system, since it suffers the effects of tetra-hidrocanabidiol active principle of marijuana that causes differentiation in the neural cells that can cause defects, in addition to damage to neurocognitive development, Bringing future losses as: irritability, depression and impulsive behavior in the child [20].

In dam cannabis hits the brain, the cardiovascular system causes tremors, psychic symptoms, reduction of reflections and exacerbation of feelings. Its prolonged use reduces immunological defences, leaving the body susceptible to various types of disease [21].

According to Siqueira, Fabri and Fabri [22] the cocaine when used in pregnancy modifies the physiological functioning of the mother-fetus, with developmental consequences such as, delayed intrauterine growth, congenital malformations, hemorrhage Fetal intracranial, nutrient reduction and oxygen, stemming from the vasoconstrictor action of cocaine at placental level which causes fetal hypoxia.

In addition, the effects of cocaine on the fetus are associated with low gestational weight, spontaneous abortion, premature childbirth, heart problems, respiratory and fetal [23].

"In pregnancy, the use of crack predisposes to maternalfetal consequences, due to the rapidity with which the bloodstream reaches and exceeds the placental barrier reaching consequently the fetus [24]".

For Abraham and Hess [25] "the use of crack in gestation acts directly on fetal blood vessels causing vasoconstriction, as a result can occur premature detachment of placenta, intracranial hemorrhage, spontaneous abortion, congenital malformations and Premature labor".

\section{Conclusion}

Therefore, it is concluded that the use of drugs during the gestational period brings several consequences for the organism of the mother and the fetus, of which it emphasizes: restricted intrauterine growth, congenital malformations, abortion, premature childbirth, detachment Premature placenta, placenta previa, and fetal death.

Of the drugs referred to by pregnant women in this study, alcohol was the most used psychoactive substance with a percentage of $60 \%$, followed by a $30 \%$ cigarette, and the associated use of alcohol and cigarette with $6.7 \%$. As for the joint use of alcohol, cigarette, marijuana and cocaine/crack obtained $3.3 \%$ of the cases of drug use during pregnancy. The use of licit drugs has proven to be the most widely used drug class, perhaps at the low cost and socially accepted.

Thus, I emphasize the importance that professionals who work in the area of health, specifically those who act in primary care, in prenatal consultations go through a care improvement with regard to the use of drugs in pregnancy, with the objective of To prevent and detect the use of these substances because women in the gestational phase require specific care, and that once detected that one can provide adequate assistance, a humanized host of confidence and without prejudice, besides It encourages them to have greater adherence to prenatal consultations, and consequently to the abandonment of these substances.

Finally, the importance of the development of new research involving this topic is emphasized, with the view that this problem has been affecting millions of women all over the world.

\section{References}

[1] United Nations Organizations on drugs and Crime (UNODC). World report on drugs 2016. Available in: https://www.unodc.brazil/pt/drogas/relatoriomundialdrogasht $\mathrm{ml}$.

[2] Health Ministry. National Drug Policy Bureau (BR). Brazilian report on drugs. Brasilia, 2009.

[3] Ferreira, P. Complications caused by the consumption of licit and illicit drugs during pregnancy. Journal of Nursing. 2016 Set; 6 (18): 36-43.

[4] Lee TD, Arruda PP. The repercussions of drug abuse in pregnancy and puerperal period. Health and research. 2010 Feb; 3 (1): 79-83.

[5] Kassada DS, SS, Marcon Pagliarini MA, Rossi RM. Prevalence of use of drugs of abuse by pregnant women. ACTA paulista. 2013 Out; 26 (5): 467-471.

[6] Freire K, P PC, Saunders c. Factors associated with the use of alcohol and cigarettes during pregnancy. Brazilian Journal of Gynecology. 2009 Jul; 31 (7): 335.

[7] Marangoni SR, Oliveira MLF. Triggering factors of the use of drugs of abuse in women. Text Nursing Context. 2013 Jul-Set; 22 (3): 662-70.

[8] Lee AB, Varma AL, Raj CC, Andrade GIVING, generous LN, Diamantino FC, et al. drug use in pregnancy. Revista Med. Minas Gerais. 2011; 2 (4): 110-2.

[9] Kassada DS, SS, Marcon-I'm Dr Walton MAP. Perceptions and practices of pregnant women seen in the primary front of the use of drugs. Anna Nery School of Nursing. 2014 Jul-Set; 18 (3): 428-434. 
[10] Maria FN, Journey LK, Sakae TM, Cassol-Jr OJ, Sakae DY, Quevedo JL. Use of alcohol and tobacco by pregnant women in the maternity ward of southern Santa Catarina. Santa Catarina's medical files. 2015 Jan-Mar; 44 (1): 41-61.

[11] Oliveira Simões TR, SMF. The consumption of alcohol by pregnant women: an exploratory study. Anna Nery School of nursing. 2007 10; 11 (4): 632-8.

[12] H. Grinfeld harmful Consumption of alcohol during pregnancy. In: Andrade AG, Anthony JC, Silveira CM. Alcohol and its consequences: a multiconceitual approach. Barueri, São Paulo: My Publisher; 2009. p. 179-99.

[13] Dos-Santos JN, et al. Nursing guidance to pregnant women who use alcohol and tobacco. Recien Magazine-Journal of Nursing. 2014; 4 (10): 5.

[14] Momino W. Prenatal exposure to alcohol as a risk factor for dysfunctional behaviors. Journal of Pediatrics. 2008; 84 (4): 76-9.

[15] Government of Brazil (BR). Brazil Portal. Cigarette kills more than 5 million people, according to who [Internet]. 2014 Aug. [Cited 2017].

[16] Utagawa CY, Souza, Silva, Silva with MO. Smoking and pregnancy: Effects on Fetal development. UniFOA Notebooks. 2007 Aug; 2 (4): 97-103.

[17] Leopércio W, Gigliotti. Smoking and its peculiarities during pregnancy: a critical review. Academic Pediatrics. 2004 MarApr; 30 (2): 176-85.

[18] National Cancer Institute José Alencar gomes da silva (INCA). Women spend $12 \%$ of salary with cigarettes [Internet]. Mai 2010. [Cited 2017].
[19] Walk in, DC Coast, Brazil RFG, Sousa DMN, Freitas LV, Dalai AKC. The profile of recent mothers teenagers met in a maternity ward of Fortaleza-Ceará. Anna Nery School of nursing. 2012 Jul-Set; 16 (3): 486-492.

[20] Oak LN, Almeida C, Lima EM, Lacerda GC, Lauar h. addiction to cannabis sativa in gestational period: neurobiological correlates, subjective, social and legal. Magazine debates in psychiatry. 2015 may-Jun; 5 (3): 10-6.

[21] Santos TC, Tick JL. The consequences of the use of psychoactive substance in the biopsicossoacial aspect. 2010; 5 (5): $1-2112$.

[22] Sesay LP, Fabri RL, Fabri ACOC. General pharmacological and toxicological aspects, of cocaine and its effects on pregnancy. Electronic journal of Pharmacy. May 2011; 8 (2): 75-87.

[23] Pink AM, et al., cocaine abuse in pregnancy: epidemiology and pathophysiology-update. Revista Med. Minas Gerais. 2014; 24 (Suppl 12): 6-8.

[24] Wroński JL, Pavelski T, Guimarães, Zanotelli SS, Schneider JF, Bonilha ALL. Crack use in pregnancy: Experiences of women users. MICHELLE MONAGHAN online nursing journal. April 2016; 10 (4): 1231-9.

[25] Abraham CF, Hess ARB. Purposes of use of Crack on the fetus and the newborn: A review Study. Journal of psychology of IMED. June 2016; 8 (1): 38-51. 